\title{
OUTCOME OF NEWBORNS WITH BIRTH ASPHYXIA
}

\author{
Shah G S , Singh R*, Das B K \\ ${ }^{*}$ B. P. Koirala Institute of Health Sciences, Dharan, Nepal
}

\section{ABSTRACT}

Birth asphyxia is one of the common causes of mortality and morbidity in neonates and the incidence is 2-9 per 1000 live borns. The present work is a retrospective hospital based observational study. Babies born at B.P. Koirala Institute of Health Sciences, Dharan, Nepal during the period from April 2002 to April 2003 with gestational age $\geq 37$ weeks with Apgar score $\leq 6$ at 5 minutes were included in the study. The aim was to study the clinical profile, the acid base parameters and the outcome of asphyxiated newborns. Babies with congenital defects, evidence of infection and maternal drug addiction were excluded from the study. All babies were resuscitated according to the guidelines of American Heart Association. Data on 50 birth asphyxia cases were tabulated and analysed. There were $10(20 \%)$ cases of severe birth asphyxia (Apgar score: $1-3$ ) and $40(80 \%)$ cases of moderate birth asphyxia (Apgar score: 4-6). Staging of hypoxic ischaemic encephalopathy (HIE) was performed according to Sarnat's staging. Thirty percent of these cases presented with various stages of HIE and the incidence was higher in low Apgar score group. The common presentations of HIE cases had depressed neonatal reflexes, seizures, lethargy, and pupillary abnormalities. The common acid base disturbance was metabolic acidosis which was observed only in babies with HIE-3. Two neonates $(4 \%)$ died during the hospital stay due to multiorgan failure and severe metabolic acidosis.

Key Words: Birth asphyxia, Hypoxic ischaemic encephalopathy, Apgar score.

\section{INTRODUCTION}

B. P. Koirala Institute of Health Sciences, Dharan ( BPKIHS ) is situated in eastern part of Nepal having modern monitoring and mechanical ventilation facilities. Birth asphyxia is one of the common cause of mortality and morbidity in neonate and the incidence is $2-9$ per 1000 live borns. ${ }^{1}$ Perinatal asphyxia is an important cause of mortality and of subsequent neurologic disabilities among the infants who survive. ${ }^{2}$ Newborn infants who sustain an acute intrapartum hypoxic ischaemic insult (HIE) of sufficient magnitude to result in longterm neurological sequele invariably have recognizable clinical encephalopathy during the first days of life. ${ }^{3}$ These infants have evidence of derangements in many organs. Their cerebral function is depressed and remains depressed for days or weeks and they frequently have seizures soon after birth. ${ }^{4}$ Among the complications of birth asphyxia, HIE and multiorgan failure are the most dreaded complications. ${ }^{5}$ The present study was to observe the clinical profile, acid base disturbance and outcome of neonates with birth asphyxia.

Address for correspondence :

Dr. Gauri Shankar Shah

B. P. Koirala Institute of Health Sciences, Dharan, Nepal.

Email: gaurishankar@hotmail.com

Received Date : $12^{\text {th }}$ Feb., 2005

Accepted Date : 14 ${ }^{\text {th }}$ May, 2005 


\section{MATERIALS AND METHODS}

It is a retrospective, observational, hospital based study. Babies born at BPKIHS from April 2002 to March 2003 with gestational age 37 weeks having Apgar score $\leq 6$ at 5 minutes were included in this study. Babies with congenital defects, evidence of infection or maternal history of drug addiction were excluded. The birth asphyxia was classified as moderate (Apgar score 46) and severe (Apgar score 1-3) according to the 5 minutes Apgar score. The study included 50 newborns with different stages of birth asphyxia. Severe birth asphyxia was found in $20 \%$ and moderate birth asphyxia in $80 \%$ cases. Blood gas analysis could be performed in 12 cases. All asphyxiated newborns required bag and mask ventilation. Endotracheal intubation was required in $8 \%$, drugs were used in $4 \%$ while $8 \%$ of cases were mechanically ventilated.

\section{RESULTS}

Among 50 cases studied, severe birth asphyxia was noted in $20 \%$ and moderate birth asphyxia in $80 \%$ of cases. There were $46(92 \%)$ term and $4(8 \%)$ post term babies. Three $(6 \%)$ babies developed HIE-1, 8 (16\%) developed HIE-2 and $4(8 \%)$ developed HIE-3. Acid base parameters were studied in 12 cases out of which 4 were of severe birth asphyxia while 8 were of moderate asphyxia. The mean blood $\mathrm{pH}$ were 6.975 and 7.2 for severe and moderate birth asphyxia group respectively. Similarly, the bicarbonate levels were 7.25 and $14.25 \mathrm{mmol} / \mathrm{L}$. Severe metabolic acidosis was found only in HIE - 3 neonates. Two babies who died had blood $\mathrm{pH}$ of 6.8 and 6.9, respectively while the corresponding bicarbonate levels were 5 and $7 \mathrm{mmol} /$ L, suggesting severe metabolic acidosis. The common clinical

\section{Table I: Clinical presentation of the cases of HIE $(\mathrm{N}=15)$}

\begin{tabular}{lcc}
\hline Hyperalertness & 3 & $20 \%$ \\
Lethargic & 12 & $80 \%$ \\
Seizure & 12 & $80 \%$ \\
Excessive bronchial secreation & 4 & $26.6 \%$ \\
Depressed sucking reflex & 15 & $100 \%$ \\
Exaggerated moro reflex & 3 & $20 \%$ \\
Depressed moro reflex & 12 & $80 \%$ \\
Dilated pupil & 7 & $46 \%$ \\
Constricted pupil & 8 & $54 \%$ \\
\hline
\end{tabular}

presentations of babies with HIE are depicted in Table I. All babies had abnormal neonatal reflexes in the form of depressed sucking reflex $(100 \%)$ and either depressed $(80 \%)$ or exaggerated (20\%) Moro's reflex. All the babies had pupillary abnormality which was either dilated $(46 \%)$ or constricted (54\%). Others features included lethargy (80\%), seizures (80\%), hyperalertness $(20 \%)$ and excessive bronchial secretion (26.6\%). The correlation of 5 minutes Apgar score with the incidence of HIE are given in Table II. The incidence of HIE
Table II: Correlation of 5 minutes apgar score and incidence of HIE ( $N=15)$

\begin{tabular}{ccc}
\hline $\begin{array}{c}\text { Apgar score } \\
\text { at 5 minutes }\end{array}$ & $\begin{array}{c}\text { Number } \\
\text { of cases }\end{array}$ & $\begin{array}{c}\text { Number of } \\
\text { HIE (\%) }\end{array}$ \\
\hline 2 & 4 & $4(100 \%)$ \\
3 & 6 & $5(83 \%)$ \\
4 & 5 & $3(60 \%)$ \\
5 & 20 & $2(10 \%)$ \\
6 & 15 & $1(6.6 \%)$ \\
\hline
\end{tabular}

was $100 \%$ in the Apgar score 2 group. The respective incidences were $83 \%, 60 \%, 10 \%$ and $6.6 \%$ for Apgar score 3, 4, 5 and 6 respectively. The incidence of HIE was $90 \%$ in severe birth asphyxia neonates while it was only $15 \%$ in moderate birth asphyxia cases.

\section{DISCUSSION}

The present study was conducted on 50 full term neonates with birth asphyxia (Apgar score $\leq 6$ at 5 minutes). Moderate birth asphyxia (Apgar score 4-6) constituted $80 \%$ of cases while rest $20 \%$ were of severe birth asphyxia (Apgar score $\leq 3$ ). These results are similar to the observations of other workers. ${ }^{6}$ Thirty percent of these babies developed HIE. The incidence of HIE was $90 \%$ in severe birth asphyxia neonates while it was 15 percent it moderate birth asphyxia group. The changes in the acid-base parameters were more pronounced in the severe birth asphyxia patients and most of them presented with severe metabolic acidosis. Other workers ${ }^{7,8}$ also reported that acid base changes were directly related to the degree of birth asphyxia. Though the 1 and 5 minutes Apgar score are poor predictors of neonatal acidosis, an Apgar score of $\leq 3$ increases the risk of low cord $\mathrm{pH} 4.8$ times. $^{9}$ Other authors ${ }^{10,11}$ also reported poor out come in neonates having low Apgar scores at birth.

Thornberg et al ${ }^{12}$ in a study on Swedish population, reported that all infants with severe HIE either died or developed neurological damage. The mortality of severe birth asphyxia neonates was $20 \%$ while there was no mortality in moderate birth asphyxia group.

\section{CONCLUSION}

The present study concludes that 5 minutes Apgar score could be a good predictor for HIE. The most common acid base abnormality is metabolic acidosis, which is more severe when the Apgar score is low. The incidence of HIE was $90 \%$ for severe birth asphyxia group and it was only $15 \%$ in moderate asphyxia neonates. The mortality rate was $20 \%$ for severe birth asphyxia while non died in the moderate asphyxia group. 


\section{REFERENCE}

1. Lefkowitz W. Oxygen and resuscitation: Beyond the myth. Pediatrics 2002;109:517-519.

2. Tin W, Wariyar U. Giving small babies oxygen: 50 years of uncertainty. Semin Neonatol 2002;7:361-367.

3. O'Brien LM, Stebbens VA, Poets CF, Heycock EG, Southall DP. Oxygen saturation during the first 24 hours of life. Arch Dis Child Fetal Neonatal Ed 2000;83:F35-F38.

4. Emond D, Lachance C, Gagnon J, Bard H. Arterial partial pressure of oxygen required to achieve $90 \%$ saturation of haemoglobin in very low birth weight newborns. Pediatrics 1993; 91:602-604.

5. Niermeyer S, Cattwinkel J, Van Reempts P, Nadkarni P, Phillips B, Zideman $D$, et al. International guidelines for neonatal resuscitation: An excerpt from the guidelines 2000 for cardiopulmonary resuscitation and emergency cardiovascular care: International consensus on science. Pediatrics 2000;106:e29.

6. Tin W, Milligan DWA, Pennefather P, Hey E. Pulse oximetry, severe retinopathy, an outcome at one year in babies of less than 28 weeks gestation. Arch Dis Child 2001;84:F106-F110.
7. Askie L, Handerson-Smart D, Irwig L, Simpson M. The effect of differing oxygen saturation targeting ranges on long term growth and development of extremely preterm, oxygen dependent infants: the Beoost Trial (Abstract). Pediatr Res 2002;51:378a.

8. Sinha SK, Tin W. The controversies surrounding oxygen therapy in neonatal intensive care units. Curr Opin Pediatr 2003;15:161-165.

9. Perlman JM, Risser R. Can asphyxiated infants at risk for neonatal seizures be rapidly identified by current high risk markers ? Pediatrics 1996; 97 :456-462.

10. Jain L, Ferre $C$, Vidyasagar D, Nath, Sheftel D. Cardiopulmonary resuscitation of apparently stillborn infants : survival and long term outcome. J Pediatr 1991; 118:778-782.

11. Nelson KB, Ellenberg JH. Apgar scores as predictors of chronic neurologic disability. Pediatrics 1981; 68:36-44.

12. Thornberg E, Thiringer K, Odeback A, Milsom I. Birth asphyxia : incidence, clinical course and outcome in a Swedish population. Acta Paediatr 1995; 84 : 927-932. 